\title{
Animacions i simulacions per a l'ensenyament de la Biologia a secundària
}

\author{
María Isabel Lacasa Millán \\ IES Joaquima Pla i Farreras, Sant Cugat del Vallès \\ mlacasa3@xtec.cat
}

A la societat actual cada cop depenem més de les noves tecnologies en la vida diària. Els centres educatius $i$ els docents que en formem part no podem quedar al marge d'aquesta revolució tecnològica.

Aquest article se centra en un tipus de recursos TIC multimèdia: les animacions i simulacions, aplicades a l'ensenyament de la biologia a secundària. A l'article se'n resumeixen les característiques, se'n comenten les estratègies d'utilització a l'aula i es valoren els seus avantatges envers d'altres recursos.

\section{Introducció}

A l'hora d'intentar ensenyar un determinat concepte als alumnes o d'explicar-los un fenomen, molts estudis coincideixen a afirmar que fer servir imatges millora la seva comprensió. A més, si les imatges són dinàmiques allò que es representa pot assemblar-se encara més a la realitat, característica que és de gran ajut en el cas de la biologia.

Segons les dades corresponents al segon semestre de 2006, publicades per I'“Instituto Nacional de Estadística" el 53,9\% dels catalans es connecta habitualment a Internet i la majoria d'ells, el $96,8 \%$ ho fa per buscar informació (EFE, 2007).

D'altra banda, els nostres alumnes de secundària solen acceptar de molt bon grat les activitats multimèdia $i$ interactives.

L'aparició d'Internet i la possibilitat de trobar material elaborat arreu va representar un gran avenç. Actualment Internet està farcit dels materials i continguts més diversos; només cal dedicar temps i paciència per trobar allò que estem buscant.

L'ús de la web com a sistema per disseminar informació -de qualsevol tema en general i de biologia en particular- ha anat augmentant considerablement en els últims anys. L'elaboració de materials multimèdia (animacions, simulacions...) ha crescut en progressió quasi geomètrica.
Els recursos TIC: animacions i simulacions

Diversos estudis demostren que l'ús de les TIC constitueix una eina metodològica alternativa, en alguns casos, a l'ensenyament tradicional ja que poden contribuir a millorar alguns aspectes dels processos d'aprenentatge.

Entre les TIC, els recursos audiovisuals són una eina molt valuosa per a l'ensenyament de determinats temes perquè ajuden els estudiants a fer importants relacions conceptuals ja que permeten il.lustrar una gran quantitat de processos i ho fan de manera molt efectiva, amb representacions 3D que solen ser d'elevada qualitat.

Korfiatis i cols. (1999) defensen l'ús d'aquests recursos per a l'ensenyament de la biologia en tots els nivells de l'educació ja que donen l'oportunitat de "presentar el material biològic d'una manera estimulant i atractiva".

Existeixen una gran varietat de recursos TIC amb els quals es poden dur a terme activitats molt diverses; però centrarem aquest article exclusivament en els recursos audiovisuals basats en animacions i simulacions. Aquests dos tipus de recursos són programes informàtics que representen o imiten fenòmens reals o irreals mitjançant imatges dinàmiques $\mathrm{i}$ que es basen en models teòrics acceptats per la ciència. 


\section{Les simulacions}

Les simulacions són programes informàtics en format multimèdia que tenen com a característica fonamental la possibilitat que l'alumne pugui modificar alguns dels paràmetres que hi intervenen, amb la finalitat de comprovar com afecta aquesta manipulació als fets o fenòmens que s'estudien.

A tall d'exemple comentarem una simulació que podeu trobar a l'adreça

http://www.indexnet.santillana.es/secundaria/recurs os/multimedia/biologia/alcohol.xls
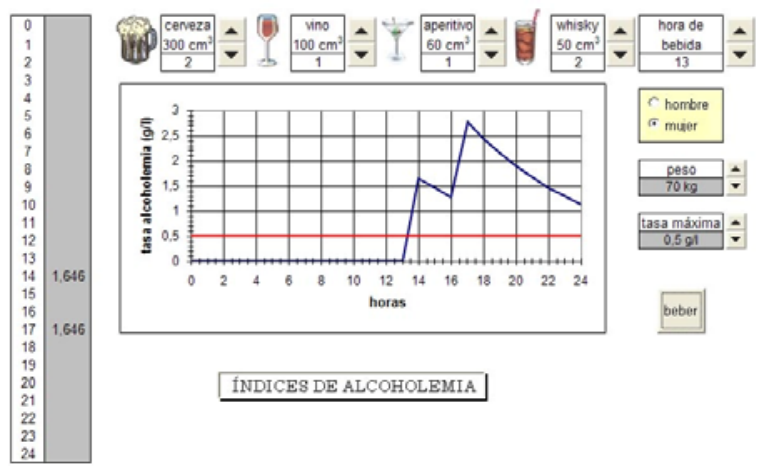

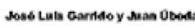

Figura 1. Simulador de l'evolució de l'índex d'alcoholèmia sota diferents condicions.

En aquesta pàgina hi ha un simulador (fig. 1) que permet determinar la taxa d'alcoholèmia d'una persona modificant diferents factors. En concret, les variables que considera són: el sexe i el pes de l'individu consumidor, el tipus de consumició i el nombre de consumicions preses, l'hora del dia en què es produeix cada consumició i la taxa màxima d'alcohol permesa.

Quan es fa córrer la simulació es presenta una gràfica en la qual s'observa el nivell d'alcoholèmia en sang en les hores següents a la primera consumició.

Com que les simulacions permeten als alumnes establir una interacció modificant paràmetres i observant els canvis que es produeixen, d'aquesta manera es facilita l'aprenentatge actiu basant-se en la idea d'aprenentatge per descobriment.

$\mathrm{Hi}$ ha estudis que consideren que les simulacions permeten als alumnes visualitzar idees abstractes mitjançant la manipulació física de les representacions dels fenòmens, així com poder examinar els resultats de tal manipulació i buscar explicacions de les causes.

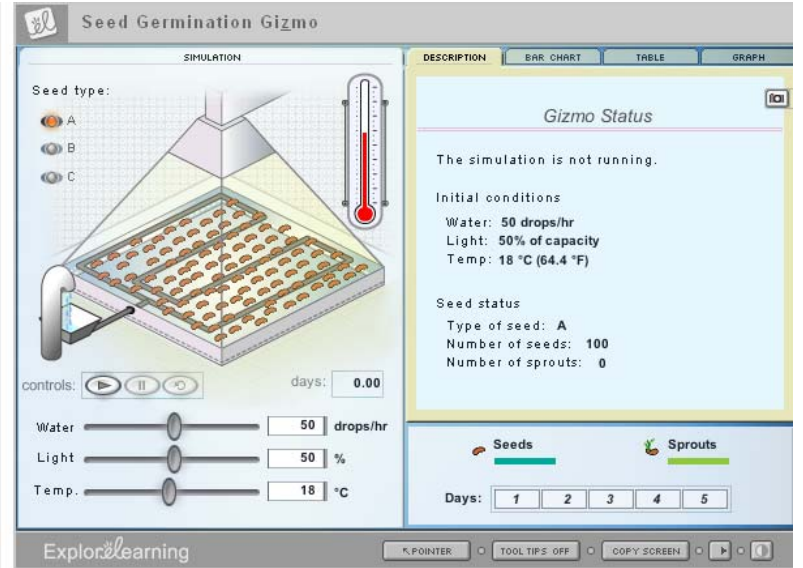

Figura 2. Simulació que estudia la germinació d'unes llavors en funció de la humitat, la temperatura i la quantitat de llum.

(http://www.explorelearning.com/index.cfm?method=cRe source. $d s p$ View\&Resourcel $D=378$ )

Bick (2006) va comprovar un impacte positiu, estadísticament significatiu, quan va fer servir simulacions de genètica per introduir conceptes teòrics com segregació dels al.lels, diferències entre fenotips i genotips, i proves d'encreuaments en alumnes de secundària entre 14 i 16 anys per comparació a grups control que no les feien servir.

Les simulacions també poden contribuir a transformar les concepcions alternatives dels alumnes i provocar canvis conceptuals en el seu procés d'aprenentatge. Aquest fet sembla més significatiu en alumnes amb dificultats d'aprenentatge. Windschit i Andre (1998) ho comprovaren explicant el sistema cardiovascular humà amb ajut de simulacions: van observar canvis conceptuals molt importants en el grup d'alumnes que treballaven amb simulacions respecte al grup control.

\section{Les animacions}

Es tracta, en aquest cas, de programes informàtics multimèdia, semblants a les simulacions, però que no permeten interacció per part de l'usuari. Fins i tot en el cas que la interacció sigui possible es sol limitar a modificar la velocitat de l'animació, fer les imatges més grans o més petites, canviar la perspectiva d'allò que s'observa... però no modificar variables del fenomen.

Una altra característica que trobem molt sovint en les animacions i simulacions és la multirepresentació dels fenòmens, és a dir, la possibilitat de veure a diferents nivells o de diferent manera allò que es representa. 
Un exemple d'animació en la què es possible aturar la imatge i que a més presenta un alt grau de multirepresentació és la que hi ha en l'adreça

http://library.med.utah.edu/kw/pharm/hyper heart1. $\underline{\mathrm{html}}$

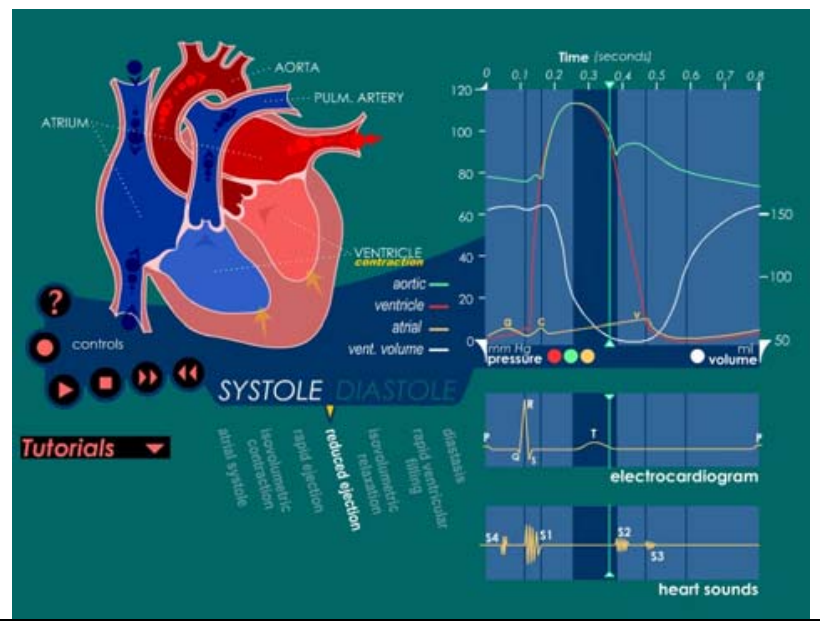

Figura 3. Animació del funcionament del cor i de l'evolució de diversos paràmetres durant el cicle cardíac.

S'hi representa (fig. 3) el cicle cardíac i es poden veure els moviments del cor, el recorregut que fa la sang pel seu interior, la variació de la pressió sanguínia en aurícules, ventricles i aorta, el volum ventricular, l'electrocardiograma i els sorolls cardíacs. A més es representa la sang oxigenada de color vermell i la poc oxigenada de color blau.

Si acceptem que les imatges en moviment són molt adequades en els casos i situacions en els què hi ha un comportament dinàmic, haurem de considerar com a adient el seu ús en el camp de la biologia en la què, per definició d'ésser viu, tot són processos dinàmics.

D'altra banda, les animacions poden proporcionar un model visual científicament més correcte dels processos microscòpics. I això, en el cas dels nostres alumnes d'ESO, poc acostumats a "imaginar-se" el món microscòpic, por ser de gran ajut. Pensem en la representació de molècules, cèl-lules, processos metabòlics...

A més, a nivell d'ESO, la biologia té una part important del currículum dedicada a la descripció; per tant la visió del que es descriu pot ajudar molt l'alumne a fer-se una "imatge mental" d'allò que està estudiant.

Tot i que les animacions no permeten modificar paràmetres, hi ha autors que defensen que una interacció, per petita que sigui, representa un avantatge sobre les animacions que no la presenten. Parant, repetint, reiniciant, fent zoom, canviant les orientacions... es poden estudiar millor les imatges dinàmiques i això facilita l'aprenentatge.

Diversos autors han fet estudis fent servir animacions amb alumnes de secundària de nivells equivalents a l'ESO sobre diferents temes: processos moleculars i cel.lulars, estudi del cor i la circulació de la sang, mitosi i meiosi... Tots coincideixen en afirmar que són molt útils ja que contribueixen a l'aprenentatge dels alumnes novells $\mathrm{i}$ ajuden a consolidar conceptes reforçant la memòria a llarg termini.

Una dada a tenir molt en compte és que aquests resultats són més efectius si els alumnes tenen uns coneixements previs sobre el tema.

\section{Els jocs de simulació}

Un altre tipus de recursos són els jocs de simulació. Es tracta de jocs d'estratègia i programes especials semblants que plantegen dilemes $i$ situacions en les què els alumnes han de resoldre de manera més o menys creativa un determinat problema.

Aquest és el cas de la pàgina

\section{http://www.edheads.org/activities/knee/index.htm}

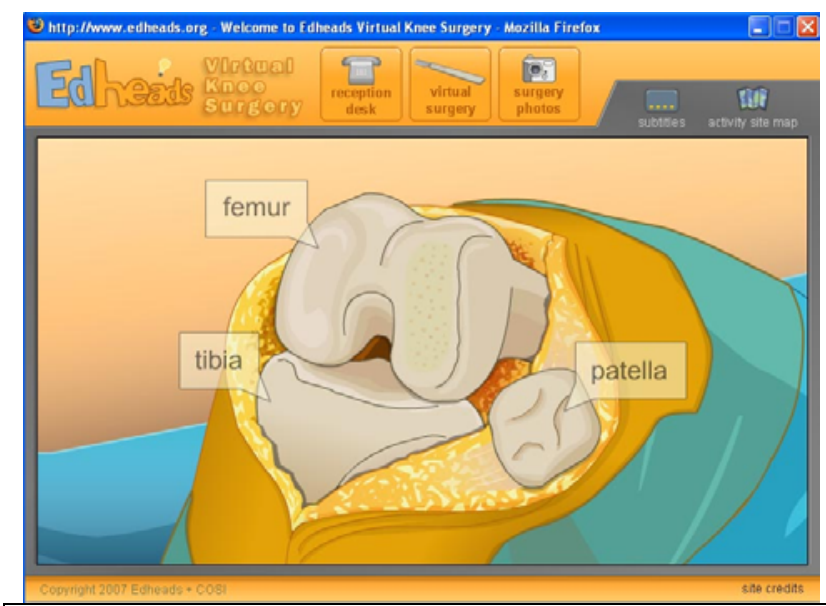

Figura 4. Simulació d'una operació de genoll.

$\mathrm{Hi}$ trobem un exemple de joc de simulació. Aquest enllaç permet entrar en una pàgina web en la qual hi ha la possibilitat de convertir-se en un cirurgià i operar un malalt que pateix un problema de genoll (fig. 4). Mitjançant aquest joc els alumnes poden reproduir les condicions que es donen en un quiròfan i tots el procés que cal seguir per dur a terme una intervenció quirúrgica. 


\section{On es poden fer servir aquests recursos?}

L'ús de tots aquests recursos pot tenir lloc:

- A l'aula ordinària si es té un canó de projecció. D'aquesta manera es poden veure situacions o fer experiències virtuals. Aleshores el treball es desenvolupa amb tot el grup classe, tot i que puntualment es poden demanar informes individuals per escrit.

- A l'aula d'informàtica. El mètode més recomanat en aquest cas serà el treball per parelles o en petits grups.

- A casa, si l'alumnat té connexió a la xarxa. En aquest cas es poden encomanar treballs individuals.

Aquesta última possibilitat és cada dia més factible i s'ha de començar a comptar-hi a l'hora de programar ja que igual que actualment el professorat podem posar deures de llapis i paper per casa, podrem anar introduint-hi activitats basades en materials multimèdia, ja que en un futur no molt llunyà treballar en xarxa serà un mètode habitual.

A l'hora de fer servir aquestes TIC, la disjuntiva entre treballar en gran grup, en petit grup, per parelles o de manera individual, depèn molt del grup classe i de la dinàmica que porta el propi professor.



Figura 5. Joc de simulació on es treballen els conceptes de transfusions i grups sanguinis.

(http://nobelprize.org/educational games/medicine/landst einer)

Treballar amb tot el grup pot facilitar el control de la classe, mantenir l'atenció dels alumnes i evitar distraccions per la seva exploració de les característiques del software. A més, constitueix un excel.lent punt de partida per començar una discussió i permet analitzar els resultats obtinguts per tot el grup classe.

Per altra part, el treball en petits grups permet analitzar, discutir i presentar les idees i troballes entre iguals.

Finalment, els treballs individuals permeten un ritme d'aprenentatge adient per a cada alumne però tenen l'inconvenient que les peticions d'ajut als professors augmenten molt i els alumnes més fluixos hi poden perdre interès.

\section{Quan es poden fer servir les animacions i simulacions?}

$\mathrm{Hi}$ ha una àmplia variació en els punts de vista del professorat sobre quin és el moment adequat per a l'ús de les animacions i simulacions. Alguns les consideren una eina de reforçament i aplicació de la teoria, mentre que d'altres les troben més adients per predir i planificar treballs pràctics. De fet, els materials al nostre abast són prou amplis com per poder ser utilitzats en diferents moments del cicle d'aprenentatge:

- Al començament d'un tema, com a activitats de presentació d'objectius, fenòmens o situacions, o bé abans d'introduir un concepte per detectar idees prèvies i preveure activitats per corregirles i posar-les en crisi.

- Al llarg del desenvolupament d'un tema, per comprovar o buscar relacions entre variables o per resoldre petites investigacions, per estructurar el coneixement o establir relacions amb altres conceptes estudiats. Fins i tot per il-lustrar un concepte de difícil comprensió per als alumnes.

- Al final d'un cicle, com a activitats d'aplicació a noves situacions, de consolidació, reforç o ampliació.

- Com una activitat científica, l'alumne pot investigar un problema abans o després de resoldre'l. Aquesta situació permet plantejar hipòtesis, identificar i estudiar el rol de diverses variables, anàlisi de resultats, contrastació amb les hipòtesis inicials...

En qualsevol cas, el moment de la inclusió d'aquests recursos en els diferents temes, la integració amb altres recursos i activitats -i les estratègies per acompanyar-les- poden diferir segons els professors i els grups classe.

En resum, la proposta metodològica seria que el professorat seleccioni el software més adient a cada moment i elabori un programa-guia d'activitats 
que orienti el treball dels alumnes i afavoreixi la seva reflexió durant el procés d'ensenyament-aprenentatge (Pontes, 2005).

Malauradament, tot i l'elevat nombre de recursos al nostre abast, aquells que presenten una guia didàctica en que s'hi inclouen suggeriments, exercicis o activitats, orientacions didàctiques, seqüènciació, temporalització... són escassos. Això implica una tasca afegida per al professor que els vol fer servir: elaborar les activitats que els alumnes hauran de fer quan utilitzin aquests recursos.

La nostra experiència és que si l'alumne es posa davant d'una animació i/o simulació sense una guió clar i pautat d'allò que ha d'observar, fer, estudiar, calcular, manipular... tot es redueix a un joc i l'aprenentatge és mínim.

Però no ens hem de desanimar: cada vegada hi ha més recursos que compten amb aquest suport. N'és un exemple el que es pot trobar a l'adreça

\section{http://concurso.cnice.mec.es/cnice2006/material03} 3/

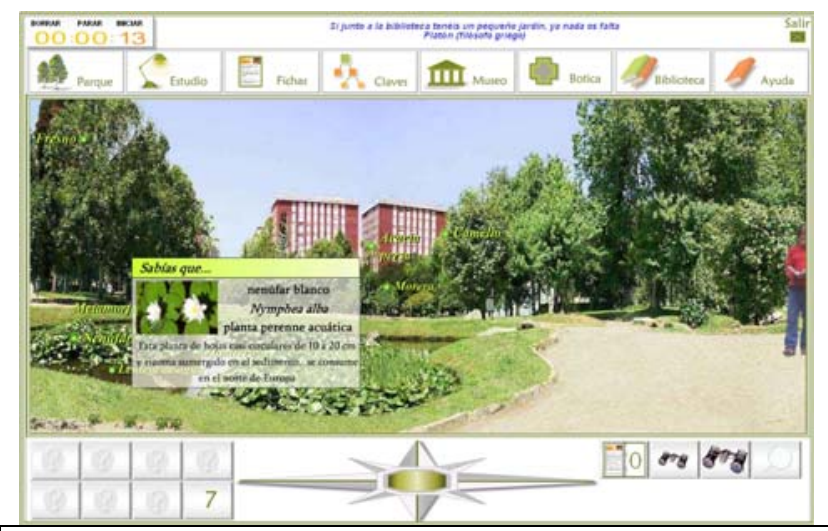

Figura 6. "Paseo por un parque virtual".

Té per títol "Paseo por un parque virtual" i, com el seu nom indica, consisteix en fer un tomb i estudiar els éssers vius que es poden trobar en qualsevol parc de les nostres latituds (fig. 6).

La gran diversitat de materials que presenta inclou una visita pel parc, podent escollir entre la primavera i la tardor i si es vol guiada o no. Cadascuna d'aquestes possibilitats compta amb tres nivells d'aprenentatge. Es poden fer activitats d'estudi sobre dotze temes diferents, hi ha claus dicotòmiques per classificar diferents grups biològics..., 0 moltes més coses. I tot acompanyat de material de suport i guies d'orientació per als alumnes i el professorat.

\section{Avantatges d'aquests recursos}

Entre els avantatges que presenten aquests recursos, aplicats al camp de la biologia, hi ha:

- Mostren una situació real que l'alumne pot modificar alterant alguna variable. Això els permet relacionar les variables amb els fenòmens $i$ els conceptes teòrics. Per exemple, l'estudi de la velocitat de reacció d'un enzim en funció del $\mathrm{pH}$, la temperatura, la concentració de substrat...

- Permeten simular un model científic i expressar les seves representacions, com els diferents models de cèl-lula (procariota i eucariota).

- Ajuden a formar una imatge mental d'un fenomen o model ja que una representació dinàmica facilita la comprensió dels processos vitals que mai no són estàtics. És el cas dels processos de filtració, reabsorció i secreció per formar l'orina a nivell de la nefrona renal (fig. 7).

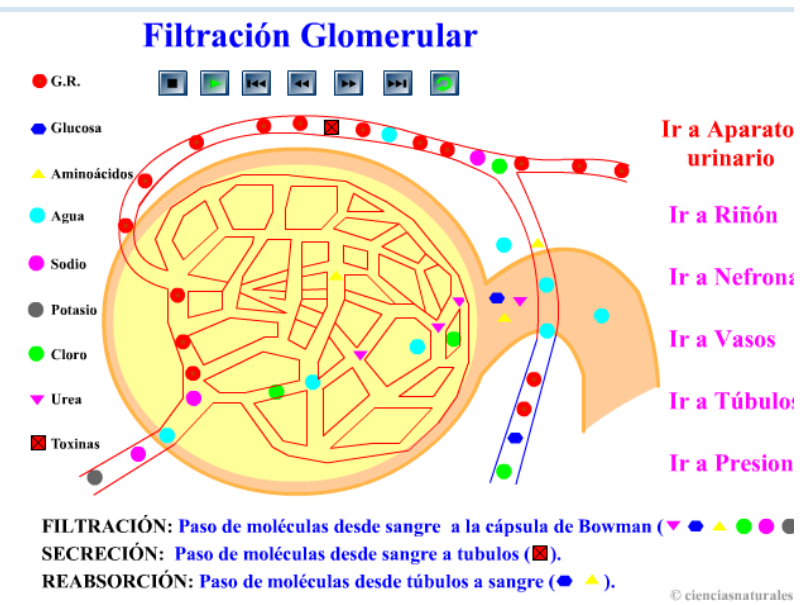

Figura 7. Animació que representa els processos de filtració, secreció i reabsorció a nivell de la nefrona renal.

(http://www.cienciasnaturales.es )

- Poden representar al mateix temps un fenomen de maneres diferents (multirepresentació). És especialment interessant en aquells casos que es pot veure alhora allò que és observable i el que succeeix a escala microscòpica, perquè permet entendre millor allò que es representa. Per exemple, la representació de la contracció muscular a nivell orgànic, cel·lular i molecular.

- Permeten dur a terme una experimentació virtual que no sempre es pot desenvolupar al laboratori per diferents motius: perill, escales de temps o espai, manca de materials... Seria el 
cas de l'estudi de l'electrofisiologia de les activitats cardíaques, nervioses i musculars. $O$ bé l'estudi de l'evolució d'un determinat caràcter en una població al llarg del temps. O, fins i tot, l'estudi de processos com la fotosíntesi o la difusió.

- Poden reproduir el treball científic fent prediccions, elaborant hipòtesis, observant i prenent dades, generant discussions, treien conclusions...

- Permeten el treball fora del centre.

- En resum, segons Hennessy i cols. (2006), aquestes eines poden ser utilitzades per incrementar les oportunitats dels alumnes per aprendre a través de participacions guiades en activitats d'investigació dins d'un particular escenari de classe.

\section{Conclusions}

La incorporació d'un recurs multimèdia depèn més de les condicions específiques d'un grup d'alumnes $\mathrm{i}$ els seus professors que del software mateix, encara que són necessàries certes condicions mínimes de presentació i organització.

Qualsevol tipus de recurs, i aquests no són una excepció, han d'anar acompanyats d'unes activitats, amb uns objectius didàctics concrets, que estiguin inserides en un cicle d'aprenentatge (Eckert i cols., 2003). Això permetrà que aquests materials no es transformin en un joc.

És per aquests motius que considerem que una guia didàctica sempre és imprescindible i que ha de recollir totes les indicacions que facilitin la implementació i aprofitament del recurs. I això, malauradament, és el que més falta en aquests tipus de recursos.

\section{Bibliografia}

Bick, A. (2006). Becoming a Virtual Organism to Learn about Genetics. ACM Press, New York USA. 13: $7 \mathrm{pp}$.

Eckert, B.; Altherr, S.; Jodl, H.J. (2003). Multimedia in teacher training. Contributin 2nd International GIREP Seminar, Udine. $6 \mathrm{pp}$.

EFE (2007). El 54\% de los catalanes se conecta a Internet habitualmente. El País, 1 de maig de 2007.

Hennessy, S.; Deaney, R.; Ruthven, K. (2006). Simulated expertise in integrating use of multimedia simulation into secondary science teaching. International Journal of Science Education, 28: 701-732.

Korfiatis, K.; Papatheodorou, E.; Stamou, G.P.; Paraskevopoulous, S. (1999). An investigaiton of the effectiveness of computer simulation programs as tutorial tools for teaching population ecology at university. International Journal of Science Education, 21: 1269-1280.

Lacasa Millán, M. I. (2007). Recull, classificació $i$ avaluació d'animacions $i$ simulacions per a l'ensenyament de la Biologia a l'ESO. Memòria de la Llicència d'Estudis Modalitat A. Curs 20062007. http://www.xtec.cat/ mlacasa3

Pontes, A. (2005). Aplicaciones de las TIC en la educación científica. Segunda parte: Aspectos Metodológicos. Revista Eureka sobre Enseñanza y Divulgación de las Ciencias, 2: 330-343.

Windschitl, M.; Andre, T. (1998). Using computer simulations to enhance conceptual change: The roles of constructivist instruction and student epistemiological beliefs. Journal of Research in Science Teaching, 35: 145-160. 